\title{
EL PES ECONÒMIC DE LA REMENÇA I DELS MAL USOS
}

\author{
GASPAR FELIU I MONTFORT
}

\section{SUMARI}

1. L'origen dels mals usos.- 2. Remences $i$ altres pagesos a la Sentència de Guadalupe. - 3. Els altres pagesos. - 4. Els pagesos sotmesos als mals usos. 5. La remença. - 6. La remença com a obstacle a la llibertat de mercat.

La finalitat d'aquest treball 'és de contribuir al coneixement de les raons del conflicte remença i fer-ho a través d'un estudi del pes econòmic que la remença, els mals usos $i$ altres servituds tenien sobre l'economia de la familia pagesa.

Les fonts utilitzades són bàsicament llibresques, però no tant bibliogràfiques en el sentit que acostumem a donar al mot en els treballs científics, com compilacions antigues, especialment les "consuetuts» i dins d'aquestes molt especialment les de Girona ', i també les obres dels comentaristes legals, sobretot Mieres, Socarrats, Marquilles i Cancer '.

1 Una primera versió fou presentada al «ll Col loqui d'Història Agrària. V Centenari de la Sentència Arbitral de Ciuadalupem, Barcelona-Olot-Girona, 9-12 desembre de 1986.

? Quan vaig redactar el treball no s'havia publicat el molt document at estudi de Josep Maria PONS I GuRI, Les col.leccions de costums de Girona. Fundació Nogucra, col. "Textos i Documents", vol. 16, Barcelona, 1988. De les diverses edicions anteriors disponibles vaig utilitzar Eduardo de HiNOJOSA, Costumbres de Geroma, Barcelona, 1926 (cext català) i Artur CORBELL.A, Consuetudines cititatis et diocesis Gerundensis, "listudis Universitaris Catalans", III (1909) (text llatí). Josep M. Font i Rius en el proleg al llibre de Pons Guri explica la procedència d'ayuestes edicions i el seu lloc dins de la traditio manuscrita dels costums de Girona (lbidem, p. 8-11).

Les altres edicions de costums utilitzades són: Joan COTS I GORCHS, Les 'consuetuds' d'Horta (avai Horta de Sant Joan) a la ratlla de Baix Aragó. "Estudis Universitaris Catalans",

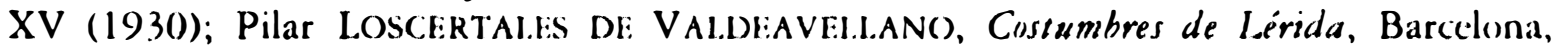
1946; Galo SÁnchizz, Constituciones hasiuliae Mirabeti, Madrid, 1915.

- Tomás Mitrlis, Apparatus super Constitutionibus Curiarum Generalium Cathaloniate. 


\section{L'ORIGEN DELS MALS USOS}

Quin és l'origen dels mals usos? A la sentència de Guadalupe es diu que la remença, la instestia, l'eixorquia i la cugucia es troben als Usatges, mentre que l'àrsia i la firma d'espoli havien estat introduïdes per costum. Però, què trobem als Usatges sobre la matèria? De remença, ni paraula; com a molt es pot interpretar que es refereixen als homes propis els usatges 91 i 102 , que parlen respectivament de Pau i Treva i de compensació al senyor pels danys rebuts pels habitants a les seves terres '. Pel que fa a la intestia, en parla l'usatge 138, que

Barcclona, 1621. Joan de SocARrats, In tractatum Petri Alberti canonici Barchinonensis de consuetudinihus Cathaloniae inter Dominos et Vasallos ac nonullis aliis, Lugduni, 1551. Jaume de MARQUILLIS, Comentaria super usaticis Barchinone, Barcelona, 1505. Jaume CANClR, Variarum resolutionum juris universalis, Caesarii, Pontificii, et municipalis Principatus Cathaloniale, Barcelona, 1594.

"hominibus eorum honorem tenentibus vel in illorum honores permancontibus sive in corum scrvicio laborantibus» (Usatge 9) $\mathrm{i}$ ude omnibus hominibus exceptis militibus, scilicet de burgensibus et de batulis atcue de rusticis, constituerunt sepedicti principes habere de emendat terciam partes seniores corum in quorum honores steterint" (Usatge 102). Com ja afirmava Vicens i Vives en contra del parer d'Eduardo de Hinojosa, no hi té ress a veure l'usatge 145, que d'altra banda és una interpolació tardana; ni encara menys l'usatge. 14, com havien preties Marichalar i Manricjue, punt ja demostrat per Piskorski; Vicens i Vives val encara més enllà: "la adscripción a la gleba, (que) no se halla citada en ninguna parte de aquel Códigon; Jaime VICENS VIVEs, Historia de los remensas en el siglo XV, Barcelona, CSIC, 1945, p. 28. Pels Usatges utilitzem l'edició a cura de Joan BASTARIDAS, Usatges de Barcelona. Fl codi a mitjans segle XII, Barcclona. 1984.

De fee l'origen de la remença continual essent desconcgut; l'ortodioxia historiogräica sobre el temal, establertal per Vicens i Vives refusal la continuitat de l'ascerviment defensada per Hinojesa i afirma cue l'obligacio de redimir-se aparcix cap a mitjan segle xill en un reforsanente de l'estattica o obligacio de resider al mas per part del pagès (Ibidem, p. 29); Salrach avancat un segle el procés, pero atfirma tambe l'existencial d'un espai de llibertat entre la servitud antiga i la noval adscripcios a la gleva: Josep M. SAI.rAch, Historia dels paisos catalans (coordinada per A. Balcells), vol. I Dels origens a 1714, Barcelona, Ed. Eilhasal, 1980, pp. 346-347. No estic tan segur que l'aparicio tardana de la redempció es degui a un empitjorament de la condició pagesa; crec més aviat que l'adscripció d'una part de la poblacioi a la terra no es va interrompre mai, si bé a partir de mitjans del segle xull es podia produir, com vol Salrach, l'acceptació de l'adscripció per part de molts pagesos lliures, perio manciats de terres, potser paral.lelament a la econcessiom als pagesos adscrits d'abandonar la terrat a canvi de lat seval reckempeici (prossibilitat inexistent o inusada anteriorment); la difusió de l'exigencia de la remensal a partir de mitjan segle xIII (o d'una major precisió documental ('n acpuest sentit), podra estar relacionada amb la possibilitat de marxar a poblar les terres de la Caralunya Noval i tambe amb la difusio del dret ronai; perio cal recordar que l'cepuiparacio (c. l'obligacio de l'afocament al colonat roma pot explicar l'adscripcios a la gleval, pero no la remença, i encara menys la subjecció a la remença de tots els membres de la familia. Per la 
segons l'ordenació de Bastardas encapçala un conjunt destinat a regular les causes successòries entre els senyors". En canvi l'eixorquia sí que apareix clarament, amb l'atribució al senyor de tot allò que pertocaria als fills si el pagès n'hagués tinguts (Usatge 109); però aquest usatge s'ha de posar en relació amb el 69, on el príncep s'atribueix els béns immobles dels nobles i magnats eixorcs. Semblantment passa amb la cugucia, que apareix com un principi general i no restringit als pagesos ". Tot i això, la fonamentació dels mals usos en els Usatges era acceptada des d'antic, com ho proven les mencions dels costums d'Horta i de Miravet, on s'afirma que els Usatges serveixen com a dret supletori, excepte pel que fa a intestia, exorquia i cugucia'.

Ens trobem, doncs, davant d'un conjunt de normes de relació feudal o bé de dret comú, que van acabar, però, recaient només sobre la pagesia. Per quin cami?' Crec que a la base hi ha una interpretació equívoca de la senyoria alodial, que en realitat engloba dos conceptes diferents: la senyoria territorial, com un cert domini sobre el conjunt del territori i dels seus habitants i, d'altra banda, la propietat senyorial, la possessió alodial de les terres de la senyoria, uns drets que, si bé acostumaven a coincidir, no ho feien sempre, sinó que hi ha prou exemples de propietats alodials diferents de les senyories territorials ${ }^{k}$. A partir

continuïtat de l'adscripció, vegeu el que he escrit, referent al Pla de Barcelona, a Jaume SOBRIQQuts (dir), Histioria de Barcelona, vol. 2, La formacio de la Barcelona medievial, Barcelona, Ajuntament de Barcelona i Fundació de l'lenciclopiedia Catalana, 19)2, capitol "Les activitats econòmiques", especialment les pp. 216-220, i Ibidem., vol. 3, La ciutat consolidada, capítol "Les activitats economiques" (en collaboració amb Antoni Ricra i Melis), especialment le's pp. 141-144.

, Usatges 138 i 76-78. Per a la col.locació dels usatges 76-78 després del 138, vegeu BASTARDAS, Usatges, pP. 15-19.

"L'usatge 1 10 no és prou explícit, però sí el 112, yue tracta de les diverses formes de prova segons la condició social de la dona.

"exceptis usaticis qui locuntur de intestiis exorquiis et cuguciis, qui non habeant locum in villa ct terminio de Hortan Cors, Les 'Consuetuts'... p. 315; "exceptat cogucias entestial ne exorquia que aci no's pague'd F. V. T. [Ferran VAI.1.S I TABI:RNIR], les costums de la batlia de Miratet, "Revista Juriclica de (Caltalunya", vol. XXXII (1926), p. 128. Cal remarcar però que en cap cas es fa menció de la remençal o era desconeguedat, o es consideral que els usatges no se n'ocupen i per tant no cal citar l'exempecio o no crat tinguda per una institució de dret públic, sinó private.

" Per una explicació més detallada i fonamentada de la diferència entre senyoria territorial i propictat senyorial, $m$ 'he de referir al meu llibre El funcionament del règim senyorial a l'Edat moderna. L'exemple del Pla d'Urgell, Lleida, 1991, especialment el capitol III, apartat 2, "Els components del regim senyorial». D'altra banda senyoria alodial té encara un altere sentit, que és el que aparcix al la documentació de l'edat moderna: la de plena propietat de la senyoria (alou) en oposició al la de concessió feudal. Així quan als capbreus de l'edat moderna els senyors es titulen senyors jurisdiccionals, alodials, territorials i campals, fan referència respectivament a la seva condició de posscëdors de la jurisdicció, de no feudals, 
d'aquesta confusió, els mals usos reconeguts als Usatges com a drets pertanyents a la senyoria territorial, que subjectaven els habitants de la senyoria als seus senyors per mitjà de la condició d'home propi i soliu, es van estendre als contractes entre particulars (independentment que un d'ells fos noble $o$ no).

Això ens encara amb una doble situació respecte als mals usos: la seva tinença per part dels senyors, per una banda, com a drets derivats iuste vel iniuste de la senyoria territorial " $i$, per l'altra, la seva imposició a partir d'un reconeixement privat, forçat o voluntari, a canvi de la possessió del mas. Evidentment ambdós sistemes podien entrar en col.lisió quan el propietari del mas, l'establidor, era diferent del senyor del lloc, però no sabem a favor de qui es resolia en aquests casos la prerrogativa d'exercir els mals usos.

Allà on els mals usos pertanyien al senyor territorial, havien anat essent suprimits, redimits o permutats en pagaments en diners o en espècie ${ }^{10} i$, d'aquesta manera, gairebé havien desaparegut a la Catalunya Nova fins al punt de fer perdre pràcticament la memòria que també aquesta zona es regia pels Usatges i que, per tant, hi eren d'aplicació els mals usos continguts en aquests ". En canvi, allà on els mals usos havien quedat en mans dels senyors

de senyors del conjunt del territori $i$ de propietaris (almenys pel que fa al domini eminent) de les terres del terme; però fora de la menció de la senyoria territorial, les altres poden faltar.

"Contra allò que sovint s'ha dit, els súbdits directes del comte no escapaven als mals usos, com es pot veure en les relacions de drets fiscals publicades per Thomas N. BISSON, Fiscal Accounts of Catalonia under the early count-kings (1151-1213), 2 vol. Berkeley, University of California Press, 1984, especialment el volum II, pp. 22-29, 94, 124-126, 140, 20)4-2(07, 216,228 i 255.

11" Els exemples de supressió dels mals usos són nombrosos dins José M. FonT RIUs, Cartas de población y franquicia de Cataluña, vol. I, Textos, Madrid-Barcelona, Consejo Superior de Investigaciones Cientificas, 1969, sobretot entre 1171 i 1281; citem només el primer, que fa referència a la carta de llibertat, amb menció expressa de l'exempció d'eixorquia i d'intestia, feta pels senyors de l'Espluga de Francolí als qui volguessin anar a poblar la vila (Ibidem, doc. 141, p. 2(22-203). Com a excmple de redempció podem citar l'acord pel qual el Capítol d'Urgell concedia als habitants d'Alàs i de Bellsolar l'exempció d'intestia, eixorquia i cugucia a canvi de 200 ) sous melgaresos (HINOJOSA, El régimen, pp. 291-292, nota 2) o bé lés 120 dobles masmudines de cens que Verdú va prometre pagar el 1231 a Poblet a canvi de l'abolició de questies, pernes i mals usos (Ibidem, p. 293, nota 1, FONT Rius, Cartas, doc. 255, pp. 363-365); o el novè dels blats que Poblet obtingué a Juncosa, els Torms i Soleràs el 1225 a canvi de la seva renúncia als mals usos i altres prestacions, inclòs el lluïsme (HINOJOSA, El régimen, p. 292, nota 2, FONT RIUs, Cartas, doc. 246, pp. 349-351).

"Precisament els anys de major concentració d'exempcions de mals usos en els documents publicats per FONT RIUS, Cartas de población, els decennis de 1210 a 1250, corresponen al moment immediatament anterior a la difusió de la remença segons Vicens $i$ Vives. 
eminents, aquests els havien afegits a l'estàtica o obligació de romandre al mas, de tenir-lo afocat, encara més quan l'estàtica es va reforçar amb la remença. De fet, on la remença no collava el conjunt, els mals usos exigits a col.lectivitats feien de mal mantenir: així ho afirmava el 1197 l'abat de Camprodon, que temia que els habitants de la vila no marxessin a poblar la nova fundació reial de Miralles (la Ral), i encara més explícitament l'abat de Banyoles el 1263, quan confessava que l'exigència dels mals usos havia fet desistir gent d'anar a habitar la vila mentre que molts que hi residien n'havien marxat, oimés considerant que la major part dels llocs reials pròxims n'eren eximits. ${ }^{12}$ De manera que els mals usos es van anar transformant d'exigència senyorial col.lectiva a prestació contractual originada en la necessitat del pagès d'obtenir terres per a treballar-les.

\section{REMENCES I ALTRES PAGESOS A LA SENTÈNCIA DE GUADALUPE}

La sentència de Guadalupe afectava pagesos sotmesos a tres situacions legals diferents: els remences, els subjectes a mals usos i els altres pagesos. Recordar això no és en va: en primer lloc evidencia que en la comesa hi havia en joc quelcom més que la llibertat personal; a més a més, atès que tots tres grups van quedar subjectes al tall imposat en la sentència ", els pagesos de remença potser eren molts menys que tradicionalment no s'ha dit: el mapa i les llistes publicades per Vicens Vives no són d'homes de remença sinó, com ja ho advertia el mateix Vicens, «de los hogares remensas y no remensas que contribuyeron en el pago de los talls" "., encara que segurament la xifra global deu correspondre bastant bé a la dels subjectes a mals usos, fossin remences o no; els «altres pagesos» que s'hi poden trobar no eren segurament pas més que els focs que, tot $i$ haver de figurar al tall, se n'havien escapolit per qualsevol raó.

Finalment, em sembla que (al recordar que la condició de remença anava lligada a la tinença d'un mas (o borda o pernada), de manera que, almenys en

12 HiNOJOSA, El régimen, apèndix V, p. $33($ )-333 i p. 292, nota 1; per Banyoles també FONT RIUS, Cartas de población, doc. 313, pp. 455-459.

" "e per que altres Pagesos que no son de remeņ̧a, ne dels dits mals Usos, son estats en dar consell, favor e ajuda (...) a perpetrar, e fer los dits crims (...) pertant condemnamlos a contribuir, per ajudar a pagar dits Pagesos de Remença la dita summa, en la qual los havem condemnats" Constitucions y altres drets de Cathalunya, Barcelona 1704, "Pragmaticas», p. 134.

11 J. Vicens Vivis, El Gran Sindicato remensa (1488-1508), Madrid, 1954, pp. 86-105; la citació correspon a la p. 86. 
teoria, els pagesos «de poble» quedaven fora de la redempció personal, si bé no necessàriament dels mals usos.

\section{ELS ALTRES PAGESOS}

Per què trobem simples pagesos, segurament emfiteutes, embolicats en la lluita per l'abolició de la remença? Sense que es pugui donar una resposta clara, no falten algunes possibles explicacions, que sorgeixen facilment de l'examen de la posició econòmica i social de la pagesia. En primer lloc, la situació del pagès emfiteuta no era pas envejable: el delme, la primícia i la tasca representaven com a mínim una quarta part de la collita neta, però sovint el cens era més elevat (quart o quint) o bé s'exigien tasca i braçatge (sota aquests o altres noms) com a censos separats; amb l'afegitó encara, quan s'esqueia, de pagaments fixats (diners, gallines) i la subjecció al lluïsme, que al bisbat de Girona equivalia a un terç i fins i tot a la meitat del valor de la finca. Això pel que fa als drets del domini directe.

Pesaven a més sobre el pagès els drets del castell termenat; aquests eren a dreta llei només els quatre reconeguts pels Usatges: sonum cornu, gayta, bada et opus foraneum, relatius a la defensa del castell; però la coacció i el costum els van ampliar amb els drets a exigir acaptes o questies, el pagament del llòssol, tant si es mantenia la ferreria de districte com si no, a rebre parts dels animals pescats o caçats ("peix de tall», "animal spenyat») i amb la prohibició de vendre vi o grans a la menuda "; i encara de vegades amb algun dels abusos citats a la sentència en la lletania que comença amb els "polls d'astor» $i$ el "pa de ca» $i$ acaba amb «femades, segades i tragines», que la sentència aboleix sempre que no es tracti d'exaccions d'origen juriscliccional ". Tot això sense comptar possibles conflictes per masos rònecs tinguts per pagesos lliures o discussions sobre redempcions de remença o de mals usos, que els senyors devien negar

1) Corbilita, Consuetudines, cap. 2 i 3, p. 545 ; el darrer aspecte es troba confirmat per la Sentència de Guadalupe: "ne tampoc pugan los dits Senyors, o Senyoras per respecte de la senyoria que sobre los dits Pagesos tenen puix no sie per respecte de la senyoria del Castell, o jusrisdictio ferlos prohibitions que no venan forment, civada, vi e altres cosas amenut». Constitucions, "Pragmaticas», p. 130.

16 "pero en aço no volem sie compres lo dit dret, si per los senyors per causa del domini, eo jurisdicció de Castell, Loc, Terme, parrochia, han acostumat rebre aquell, e aço mateix diem de qualsevol dels nous drets sobredits». Constitucions, L. IV, tit. XIII, 2 p. 130. Alguns d'aquests drets van sobreviure, possiblement emparant-se en aquesta excepció; vegeu p.e per la mesada del vi, Fel.IU, El régim (loc. cit.), i especialment el Quadre I. 
emparant-se en capbreus antics "17 o la por que els senyors, en cas de triomfar, acabessin subjectant a remença tota la pagesia.

\section{ELS PAGESOS SOTMESOS ALS MALS USOS}

La submissió als mals usos comprenia en principi pagesos de tot el Principat, però a la Baixa Edat Mitjana el seu àmbit havia anat quedant reduiit a la Catalunya Vella ${ }^{1 /}$, on d'altra banda només una part dels pagesos hi continuaven obligats.

Pel que fa a la seva incidència econòmica sobre la família pagesa, no hi ha cap dubte que el mal ús més gravós era la intestia, per la qual el senyor tenia dret a una tercera part dels béns mobles, inclosos semovents, censals i expectatives d'herència (legítimes), de l'home propi i dels membres de la seva família morts intestats.

En teoria bastava testar per a defugir la intestia, però la casuística legal i la coacció senyorial havien trobat camins ben esbiaixats d'aprofitament. Per entendre-ho cal aclarir la categoria d'intestat $\mathrm{i}$ els drets hereditaris de cadascun dels membres de la família. En primer lloc es discutia el significat del terme «intestat»: mentre que Jaume de Montjuiic i rera d'ell molts advocats de Barcelona consideraven intestada qualsevol persona morta sense haver fet testament, en canvi a Girona, i així quedà recullit als Costums, només es considerava intestat el mort que no havia testat tenint capacitat per a fer-ho, opinió que Mieres i Socarrats avalen i fonamenten legalment ". Però que els millors tractadistes recluïssin a termes lògics la intestia no vol dir pas que la seva doctrina fos més seguida o simplement que els senyors no utilitzessin el seu poder de coacció per a rapinyar al màxim els béns dels seus homes propis "'.

Almenys alcuesta cuecixal val ser prescentada pels pagesoss a figural en el projecte de conciordia de 1462; HINC)(OSA, El regimen, apiendix XI, p. $36,5$.

in Vegeu sobre aixi) Prancesc Carrlikas CAND), "Contestación", al liduardo de HINOJOSA, Origen y vicisitudes de la pagesia de remensa en Cataluña. Discursor leidos en la Real Academia de Buenas Letras de Barcelona en la recepción de D. E:duardo de Hinojosa el dia 16 de marzo de 1901. Barcelona, 19)2.

1) aideo est optima consuctudo Gerundac cuod de bonis pupillorum non debet solvi, nec exhigi intestia nec exorquia et pecant contrat observantess COR BB:LI.A. Consuetudimes, rub. 27, cap. 6, p. 334. MIt:RI:S, Apparatus, II, fols. 4-11. SocARrats, In tractutum, pp. 221 i 5(1), que es basen en la distinció entre intestedbilis i intestatus, essent aquest darrer l'únic sotmès à intestia.

"2 Un cas ben especial, perio demostratiu d'acpuesta coacció es el del rector de Torrelles 
En el pitjor dels casos la intestia era exigida a cada defunció no acompanyada del corresponent testament; això comportava per al pagès i per a la seva muller la molèstia $i$ despesa de testar $i$, encara pitjor, feia planar l'ombra senyorial cada cop que moria un fill, fenomen tan dolorós com freqüent. Què podia posseir un infant de pocs anys? Si era l'hereu, la quarta trebel.liànica, o sia la part de lliure disposició de l'hereu gravat que el remença era per definició; si no l'era, la legítima o legítimes que li poguessin correspondre o els drets a l'herència de l'ascendent $\mathrm{o}$ ascendents difunts. Cada intestia suposava a més a més la molèstia i la despesa afegida de la intromissió dels oficials senyorials amb l'excusa de portar a terme els càlculs consegüents, sovint prou envitricollats: cadascun dels pares podia reclamar la legítima de la legítima o d'altres béns procedents de l'altre cònjuge (el pare de la mare i viceversa) del fill mort ${ }^{21}$; d'altra banda, els senyors reclamaven el terç que els pertocava sense fer deducció de deutes $i$, de fet, Socarrats afirma que els deutes només s'han de deduir si les dues terceres parts restants o bé els béns immobles resulten insuficients per a satisfer els creditors ${ }^{22}$.

Encara més, si l'intestat era vidu, sembla que alguns senyors exigien fins a la meitat dels béns mobles que li pertanyien d'acord amb allò que establia l'usatge $1.38^{\prime 2}$, pràctica a la qual veiem oposar-se Socarrats ${ }^{24}$, de la mateixa manera que, fidel a la seva idea que, en cas de dubte, calia afavorir la part més dèbil, defensa que si bé s'ha de pagar intestia del fill mort fora del mas sense testar, això només és així si la mort d'aquest es produeix després de la del pare, pràctica que no devia ser gens habitual i que el mateix Socarrats sembla contradir pàgines més avall, quan discuteix si pertany al

cap a 1300, que era a la vegada batlle del poble i que es va negar a anar a confessar i a rebre el testament d'una malalta de la qual, un cop morta, en va exigir la intestia. J.M. Marti Bonet, L. Niqui Puigivert, F. MiQuel. i Mascort, Processos de l'Arxiu diocessá de Barcelona, Barcelona, 1984, p. 103.

"MIERES, Apparatus, fols. 11 i 15 , on copia un dictamen del consell reial sobre la matieria.

2 SOCARRATS, In tractatum, p. 512.

"L'usatge 138 (BASTARDAS, Usatges, p. 150), diu que correspon al senyor per intestia la tercera part dels béns, sense fer la restricció als béns mobles, si l'intestat deixa dona i fills, però si només deixa dona o fills, la taxa és la meitat. Per això ja feia observar Marquilles que "usaticum non servatur eo modo quo littera resonat»; MARQUII.LES, Comentaria, fol. CCXCII v.

$\because$ SOCARRATS, In trattatum, p. 506, "dominus de bonis mobilibus rustici intestati sive cum filiis et uxore decedat, sive cum filiis, et non uxore, sive alias, non habet nisi dumtaxat tertiam partem.» Afegia Socarrats que caldria suprimir la intestia, atès que havien cessat les causes que l'havien fet convenient i que segons Socarrats eren el fet que, morint el pagès intestat, es suscitaven litigis entre els fills a causa de l'herència: la difusió del costum de l'hereu primogènit ja evitava qualsevol discussió. 
pare l'usdefruit del terç pertocant al senyor en els béns del fill mort intestat ${ }^{25}$.

La mort no solament podia colpir econòmicament la família pagesa per la intestia; ho podia fer també igualment per l'eixorquia, amb taxes $\mathrm{i}$ per raonaments semblants, car alguns senyors consideraven eixorcs tots els morts sense fills i majors de dotze anys, atès que a partir d'aquesta edat eren considerats capaços de generar; i també aquells qui, havent tingut fills, no en tinguessin de sobrevivents, si bé uns altres tractadistes reduien el dret a l'eixorquia als casats o als solters majors de trenta anys ${ }^{20}$.

Una altra qüestió sorgia quan s'acumulaven les condicions d'intestat $i$ d'eixorc; en aquest cas alguns autors, com Jaume Desfar, afirmaven que el senyor podia acumular ambdues prestacions o com a mínim obtenir la meitat dels béns del difunt, si bé Socarrats replicava que, fos quin fos el cas, la part del senyor no havia de superar el terç i que intestia i eixorquia no eren acumulables, tal i com s'afirmava també en els Costums de Girona ${ }^{27}$. Podem afirmar, doncs, que la sovintejada visita de la mort representava, per obra de la intestia i de l'eixorquia, una punció constant per a l'economia dels pagesos subjectes als mals usos, al mateix temps que una font de conflictes amb els senyors.

Darrera de la intestia i de l'eixorquia cal considerar la importància de la firma d'espoli o d'esponsalici forçada, dita també entrada al mas (intrata mansi); es tractava d'un abús introduït en convertir en obligatori i remunerat el permís firmat del senyor per a assegurar el dot de la muller i el seu escreix sobre els béns del mas. Aquesta cautela voluntària l'havien convertida els senyors en una font més d'ingressos, de manera que l'home propi havia d'assegurar sobre el mas almenys la meitat del dot i de l'escreix, encara que tingués uns altres béns on encarar-ho. Aquesta coacció reportava al senyor dos sous per lliura, o sia un $10 \%$ del valor asegurat o un $5 \%$ del valor del dot i l'escreix ${ }^{24}$.

"SOCARRATs, In tractatum, "ubicumque filius familias decesserit intestatus, dominus habet tertiam partem bonorum (...) Intestia debetur de bonis mobilibus filii familias intestati decessi post mortem patris: ergo a contrario sensu, si decesserit vivente patre, nulla intestia deberetur" p., 5()2. "Quaero quid si filius familias habeat bona mobilia adventitia, et decedat intestatus, numquid in illa tertia parte domino competenti habebit pater usufructum" p. 505 .

26 Marquilles, Comentaria, fol. CCXCIII, aporta les dues opinions sense pendre partit; també SOCARRATS, In tractatum, p. 517, que creu que només hi estan subjectes els casats; Mieres, Apparatus, p. 11 , també exclou els impúbers: «quia pupillus propie non est exorchus nec dicitur sterilis, nec est infoecundus: quia aetate naturaliter impeditur generare et quae natura facit vel negat, imputari non debet (...) Quidam tamen de facto contrario) hodic observant".

27 SOCARRATS, In tractatum, pp. 507-510, CORBEll.A, Consuetudines, rubr. 27, cap. 3, p. 252 .

${ }^{28}$ Corbeil.a, Consuetudines, rubr. 39, cap. 1, p. 450 . 
Els dos darrers mals usos clàssics eren realment molt més aleatoris: mentre que el pagès difícilment podia escapar-se dels tres primers $i$, fins i tot, la família s'hi podia veure sotmesa repetidament, la possibilitat d'haver de pagar per àrsia o cugucia era molt més escadussera, si bé sobretot l'àrsia sobrevenia en un moment prou difícil per a l'economia pagesa.

Queda un darrer mal ús, gairebé diria el principal, el qual, però, no acostuma a ser posat en llista amb els altres i que altrament és el més mal conegut en les seves implicacions reals. Es tracta del dret a prendre i maltractar, que posava en mans del senyor la persona i els béns del pagès, sense que aquest pogués acudir en queixa a cap instància superior i sense que el senyor hagués ni tan solament de justificar els motius dels seus maltractaments. Passa, però, que costa de creure que amb una tal arma a les mans els senyors es veiessin engavanyats $i$, finalment, vençuts pels seus pagesos: sembla que no hauria d'haver estat gaire difícil per als senyors aplacar les sublevacions empresonantne els cabdills i, també, que tota la casuística, per exemple sobre la intestia, era absolutament inútil si el senyor era amo d'arrabassar sense més explicacions els béns dels seus pagesos.

El text de la Constitució de Cort de Cervera de 1202 és, però, ben clar: «Si los Senyors lurs pagesos maltractaran o las suas cosas a ells tolran (....) en nenguna manera sien tenguts al senyor Rey en alguna cosa» "; podria quedar el dubte del sentit d'aquest paràgraf posat dins d'una constitució de pau i treva i pensar que no es tractava de donar carta blanca als senyors per a maltractar o desposseir els seus homes propis, sinó de salvaguardar els senyors davant possibles represàlies del monarca pel trencament de pau i treva, com les que el rei podia intentar en casos semblants sobre els seus feudataris "'o els tenidors de senyories eclesiàstiques "; com es deia en el dictamen d'un jurista de mitjan segle XIV, la Constitució de Cort de Cervera no diu que sigui lícit al senyor maltractar els seus pagesos, sinó que, si ho fa, no n'ha de respondre davant del

"Constitucions, 1, p. 494, recollit en els Costums de Girona: «Item costum que cascun senyor pot pendre son home propi i tenirlo pres sota tina o tavegan HINOJOSA, Costumbres, rubr. 25.

"SOCARRATS, In tractatum, p. 182: "Quaero si dominus castri maletractat vasallos castri, quod remedium habebunt. Dominicus de Sancto Gemi. (...) dicit quod privatur a feudo. Bal. (...) dicit quod dominus rex potest monere cum quod eos tractet modo debito et consucto: alias poterit auferre castrum». MARQ(HII.IFS, Comentaria, fol. CXI.V, cita un cas de perclua de feude per haver maleractat els vassalls.

"De tota mancra alguns senyors eclesiàstics com el monestir de Sant Llorenş del Munt, s'irrogaven el dret at maltractar el seus pagesos. HiNojosa, El régimen, pp. 97-98, cita també el cas de Pedralbes, però és dubtós, ja que el document diu que el monestir té la juriscliccio civil i sembla que és en virtut d'aquesta que al.lega el dret a empresonar i castigar legalment, que no te res a veure amb el dret a maltractar. 
rei ". Si més no, el dret a maltractar consta clarament als Costums de Girona" però, considerant el moment de la compilació d'aquests, podria no ser un dret antic sinó l'aplicació de la Constitució de Cervera.

La majoria dels legistes hi estaven decididament en contra; només alguns defensaven la validesa del precepte legal, tot i trobant-lo injust "4; Mieres, en canvi, afirma rotundament que el senyor no pot actuar contra el pagès sense justa causa ni procés i que ni al rei amb les corts no els era lícit de fer una llei iniqua i contrària a la llei de Déu, de manera que no dubta a considerar furt $\mathrm{i}$ rapinya l'exercici del dret de maltractar".

Davant l'evidència de la "legalitat» del dret a maltractar, és difícil d'entendre el poc ús que semblen fer-ne els senyors ". Les hipòtesis explicatives, totes bastant fluixes, $s$ 'han de buscar en la pèrdua que el senyor experimentava en les seves rendes si el pagès no treballava la terra; en la possible pressió de la comunitat de poble sobre els senyors laics alodials per a limitar el dret a maltractar; i, possiblement per damunt de tot, en el fet que els pagesos aconseguien de tota manera que els plets per maltractament fossin acollits per la justícia reial; així sembla desprendre's a contrallum d'una carta que, el 18 de gener de 1384, el rei Pere III escrivia a l'infant Joan, lloctinent del Principat: «sobre lo maltractar que.s diu que lo comte d'Urgell fa dels homens del Castell e baronia de Cervelló (...) havem trobat que lo dit Comte ha assignat jutge als dits homens sobre la qüestió que ha ab ells per la qual se diu que.ls maltractava (...) per que per justicia aquells homens no poden esser dits maltractats ne per conseguent no per rahó de maltractament ne vos no us en deveu entremetre." "

". "Constitucio que fuit facta Cervaric non dicit quod aliquis possit male tractare homines suos, nec bona cius aufferre, sed dicit quod si fecerit, non teneatur domni regi». Paul Frffodman, The catalan ius maltractandi. A: Université de Montpellier, "Recueil de mémoires et travaux publié par la socièté d'Histoire du Droit et des Institutions des Anciens Pays de Droit Écrit», fasc. XIII (1985), p. 43.

"CORbilla, Consuetudines, XXXV, cap. 1.

"Vegeu dos dictamens oposats publicats per likbloman, The calalan, apendix.

" «non licet dominus occupare bona sedentia hominum suorum, nisi facto processu et ex causa iusta (...) Rex etiam cum total curia nom potuit, neyue posset facere legem iniquam (...) auferre res suas rustico, vel homini etiam propio, et solido, sine iusta et rationabili causa, est committere furtum et rapinam (...) et ipsi rustico maletractato competunt actiones, et remedia iuris contra dominum». MIrRES, Apparatus, pp. 513514. SOCARRATS, In tractatum «non licet domino castri etiam habenti omnimodam iurisditionem, inferre vim habitatoribus dicti castri, ctiam si essent de redimentia" (p. 179).

"Al projecte de concòrdia de 1462, aquest dret sembla objecte d'una doble limitació: "Item en moltes parts del dit principat de Cathalunya alguns senyors" HINOJOSA, El régimen, apèndix XI, p. 366 (els subratllats són meus); d'altra banda, arribat el moment, els senyors hi renunciaren sense cap resistència.

"ACA, Cancelleria, vol. 1105 , fol. 64 v. E:I 1448 la reina Maria escrivia queixant-se 
El fet que s'al.legui una raó per no intervenir indica que, en cas de maltractament, la intervenció reial era possible.

\section{LA REMENÇA}

El pagès home propi, soliu, afocat i subjecte als mals usos podia abandonar la terra, però a condició de vendre-la a qui pogués acceptar $\mathrm{i}$ acceptés subjectarse a la situació del venedor; en cas contrari només podia marxar abandonant la terra en mans del senyor ${ }^{38}$; el remença no ho podía fer si, a més a més, no es redimia " $\mathrm{i}$ aquesta redempció podia ser ben onerosa: els Costums de Girona diuen que el senyor només estarà obligat a concedir la redempció si el pagès adquiria un mas en un altre lloc o si hi entrava per casament; en aquest cas el senyor tenia dret a una tercera part dels béns mobles, igual com si el pagès hagués mort intestat o sense descendència, si bé hi havia senyors que exigien també el terç dels immobles ". Fora d'aquests casos el preu de la redempció havia de ser pactat; Serra i Vilaró aporta alguns exemples de redempcions a l'alta vall del Llobregat i mostra com el preu va pujar enormement després de la pesta negra: mentre que la redempció més cara anterior al 1348 era de 10 lliures (200 sous) i gairebé mai no arribava a les $5 \mathrm{ll}$., després de la pesta el mercader de Ripoll Ponç ses Viles hagué de pagar 150 ll., si bé es tracta d'un cas excepcional "; la mateixa evolució mostren el pergamins conservats a Arenys de Mar, si bé en conjunt amb redempcions més baixes ${ }^{42}$.

dels mals tractes que el baró Bernat Gilabert de Crüllles havia fet a remences súdits seus. Santiago SOBREQUÉS I VIDAl., La política remenfa de la monarquia en temps d'Alfons el Magnànim, a: Santiago SOBRI:QUIÉS I VIDAL, Jaume SOBREQUÉS I CALLICÓ, La guerra civil catalana del segle $x V$, vol. I, Causes $i$ desenvolupament de la irisi. Barcelona, 1973, p. 19.

is Constitucions, lib. IV, tit. XXXII, cap. 1, p. 347, constitució «En las terras...»: «En los Lochs empero, hon los Homens no han acostumat de reembre, si mudan lur estage als locs nostres, retudas las cartas lexen a lurs senyors propis lurs possessions, o que les alienen a persones no vedadas", ampliada amb la constitució "Commemorants", p. 348.

19 Així s' indica a les constitucions citades a la nota anterior, reforçades pel comentari de MIERES, Apparatus, cap. XXVIII, p. 90: «Qui mansum vel bordas deservit, cedentia bona amittit, et tenetur se redimere, si fuerit de loco ubi est consuetudo redimendi».

"Corbilla, Consuetudines, p. 59.

"Joan Serra Vil.aró, Baronies de Pinós i Mataplana, Barcelona, 1930, II, p. 334.

12 Josep Maria PONS GURI, Inventari dels pergamins de l'Arxiu bistòric "Fidel Fita" d'Arenys de Mar, Barcelona, 1984. He revisat les redempcions entre 1250 i 1450); deixant de banda les donzelles redimides a la taxa de 2 s. 8 d., els resultats en sous són els següents (entre 
De tota manera la redempció de tota la família o del cap de casa era poc corrent: només l'accés per herència o per casament a un mas millor n'eren normalment les causes; si no es donaven aquestes condicions, el pagès no acostumava a voler abandonar la terra. De manera que el pes econòmic de la remença no s'ha de veure tant en relació amb el cap de casa com amb els fills: el casament de cada fill comportava la despesa addicional del pagament de la remença, que era baixa i automàtica per a les filles solteres, $2 \mathrm{~s}$. $8 \mathrm{~d}$. que bastava depositar damunt de l'altar abans del casament "; en canvi, per als fills solters o per a les vídues que es volguessin tornar a casar i canviar de domicili, la cosa era molt diferent. Segons els Costums de Girona, els fills mascles, si sortien del mas per casar-se, estaven obligats a redimir-se, però el senyor no els podia exigir més d'una tercera part dels béns mobles comptanthi allò que els pogués pertocar com a legítima ${ }^{14}$; en un altre cas el senyor no podia obligar el fill del pagès, home o dona, a redimir-se ni en cas que se n'anés del mas (quedava sempre a la reserva per a fer-se càrrec del mas si morien els germans més grans); però si se n' anava, el senyor el podia obligar a fer-li reconeixement de senyoria i pagar-li un cens (un parell de gallines o cosa semblant). Ara bé, si el cabaler (iuvenis homo) demanava redimir-se, el preu podia ser més elevat: els Costums de Girona diuen en un punt que el senyor poterit habere quicquid et quantum inde potuerit convenire, encara que en un altre apartat s'hi afirma que la tarifa era en aquest cas un terç dels béns mobles i immobles ". La vídua del remença, si es volia tornar a casar, havia d'obligar el nou marit a fer-se home de remença del seu senyor; en cas contrari, podia ser obligada a redimir-se i era expulsada del mas, si bé conservava el seu dot ${ }^{\text {t" }}$.

Hi havia també casos en els quals el senyor no estava obligat a concedir la remença: al pagès propietari del mas, fora de les situacions esmentades més amunt, o sia, fora que la demanés per a constituir-se en remença d'un altre senyor ", o a la seva filla pubilla; encara més, si la senyoria era eclesiàstica el senyor no podia concedir la redempció a cap preu ni al pagès ni a la pubilla ${ }^{\text {th }}$, ja

parèntesi el número del pergamí): $1303(173) 20$ s.; $1315(2.37)$ 8() s.; $1336(326) 20 \mathrm{~s}$; $1.349(434) 150$ s.; $1350(441) 25$ s.; $1352(445) 80$ s.; $1386(712) 140$ s.; $1398(772) 220$ s.; $1409(848) 22$ s.; $1436(970) 33$ s.; 1439 (986) 150 s.; $1447(1017) 77$ s.

"CORBrlla, Consuetudines, p. 59.

"Hinojosa, Costumbres, p. 10, CoRbril.ta, Consuetudines, p. 59.

"Hinojosa, Costumbres, p. 36, Corbilila, Consuetudines, pp. 59 i 341-342.

"Ibidem, p. 59.

"Ibidem, p. 249: "nullo tamen casu potest rusticus dimittere mansatam pro qua praestitit homagium solidantiae, nec mansum renuntiare in diocese Gerundense invito dominom.

1s Ibidem, p. 59. 
que no li era lícit a l'eclesiàstic usufructuari de la senyoria permetre la minoració dels seus béns.

A desgrat d'aquesta casuística, la remença, des del punt de vista estricte de la despesa econòmica que representava, no ha de ser considerada com el més fort dels mals usos, si bé és evident que era el principal suport de tota la resta; i tampoc no evitava l'abandó pràcticament definitiu del mas per la força de treball innecessària, si bé aquesta quedava exposada a desagradables sorpreses, com la d'aquell aprenent de sastre a Barcelona que va ser comminat a anar a "afocar» un mas que feia més de deu anys que estava abandonat "; o la del burgès de Barcelona, que comprà un mas a Badalona i es va trobar després perseguit pel senyor, que volia reduir-lo a la condició de remença".

\section{LA REMENÇA COM A OBSTACLE A LA LLIBERTAT DE MERCAT}

La sublevació dels pagesos de remença va ser sens dubte en gran part una sublevació de la misèria, una sortida desesperada a una situació que per a molts era difícilment suportable: la quantitat de masos que no van poder afrontar els 6) sous fixats en la sentència de Guadalupe com a redempció dels mals usos i que trobem a l'edat moderna pagant els censos alternatius en són una mostra ben clara ". Però en altres casos devia ser també una sublevació contra uns obstacles socials $\mathrm{i}$ econòmics que travaven les possibilitats de guany d'una pagesia més benestant.

Voldríem en aquest sentit examinar i aportar com una explicació més de les causes de la revolta els obstacles que la remença representava per al mercat agrari i també per a l'estratègia d'unions familiars, font ràpida i segura de creixement econòmic en les economies tradicionals.

En principi el pagès sotmès als mals usos, tant si cra de remença com si no ho era, podia vendre, permutar, sotmetre a cens i comprar terres, si bé no pas sense entrebancs: el dret a vendre terres del mas era negat per alguns o en alguns llocs, els possibles compradors havien d'acceptar la situació legal dels venedors (cosa que pràcticament eliminava els possibles millors oferents, pagesos lliures o bé burgesos) i el senyor podia prohibir la venda si considerava que les terres restants resultaven insuficients pel manteniment del mas i, si més no, tenia dret

"Sirra Vit.aro, Les baronies, vol. I regesta n. 84, de 5 de març de 1335.

"HINCJOSA, bl régimen, p. 222, n. 2.

"Encara a finals del segle XVIII es troben pagesos pagant pels sis mals usos. Montscrrat Duran I Pujot., Renda i producioi agraria a Catalunya, Tesi doctoral inedita, Universitat Autionoma de Barcelona, 1984, vol. II, p. 655. 
al terç de la venda "; les terres comprades pel pagès quedaven incorporades al mas i corrien el perill de caure sota el domini del senyor: segons els Costums de Girona, la terra comprada pel pagès podia ser venuda en vida d'aquest abans dels trenta anys de la seva adquisició "; mort, però, el pagès o exhaurit aquest termini, la terra quedava incorporada al mas i no podia ser venuda sense consentiment del senyor i satisfacció de terç i lluïsme " D'altra banda, tota terra en possessió del pagès era considerada com a pertanyent al mas, llevat que el pagès pogués documentar que es tractava de terra alodial".

Vora les dificultats per a la compra-venda de terres cal situar les traves a la política matrimonial. El fet que estigués vedada la redempció dels remences de senyories eclesiàstiques i dels seus hereus i pubilles és molt possible que no sigui aliè a l'especial virulència que la pugna tingué en les terres de senyors eclesiàstics: quedaven impedits, així, els casaments hereu-pubilla $\mathrm{i}$ fins i tot la possibilitat de canviar el mas per un altre de millor; els remences benestants sota senyoria eclesiàstica trobaven, doncs, un obstacle addicional en el camí del seu progrés econòmic.

En aquest sentit la sentència va ser clarament liberalitzadora. En endavant, el mercat de la terra va quedar obert sense restriccions, com ho prova un exemple que ens servirà per a acabar: l'any 1568 el donzell Jaume Joan de Solanell venia cinc masos a Armancies, obligats, entre altres prestacions, a pagar 3 sous cada any al dispeser major del monestir de Ripoll per raó de la commutació dels mals usos feta a la sentència de Guadalupe ": ens trobem, doncs, davant d'un noble subjecte als mals usos, situació evidentment impossible abans de la Sentència de Guadalupe.

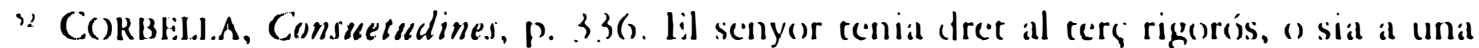
meitat del producte de la venda, si bé acostumava a renunciar a un ters del ters, de manera que la quantitat que rebia era una tercera part del valor de la venda, peri) el pages havia de pagar 2 s. més per lliera al batlle, de mancera que toe plegat se n'anava a un $4.3 \%$. Si es tractava d'una permuta els drets senyorials, sobre el valor estimat del be, cren mig ters i mig lluïsme, o sia un 30\% (25\% pel mig ters i $5 \%$ pel mig lluïsme).

"En aquest cas el senyor nomes tenia dret a 2 s. per ll. (5\%) "pro exita mansi". lbidem, p. 3.38.

"Ihidem, Pp. 153-154, Hinojosa, Costumbres, p. 15.

"Corbill.a, Consuetudines, p. 453.

" "vigore regie sententic pro talis usibus dictorum mansorum inter seniores ex una et pagenses de redimential ex altera partibus per serenissimum dominum regem Ferdinandum laten; SFrRa VII.AR(), lees baronies, regestal n. 157. 


\section{RÉSUMÉ}

Le but de ce travail est de contribuer à faire connaître les raisons du conflict que suppose la rançon en recherchant ses effets à travers l'étude des charges économiques que la dite rançon, les droits de servage et autres servitudes impliquaient pour les paysans qui y étaient soumis.

On y discute de l'origine des droits de servage, de son établissement sur la paysannerie des fermes, de la portée de la Sentencia de Guadalupe, qui n'affecte pas seulement les serfs, mais aussi les "autres paysans», de la casuistique légale, qui devait la payer, quelle en était le montant et dans quelle proportion elle se payait; on y parle aussi du manque d'effectivité du droit de mauvais traitements.

On peut en conclure qu'en dehors des intestats et dans certains cas, rares, de la rançon, les droits de servage n'étaient lourds que pour les paysans les plus pauvres, car les paysans aisés n'étaient freinés dans leurs possibilités d'amélioration économique que par l'obstacle que représentait l'interdiction d'abandonner la ferme, ce qui entravait le marché de la terre et faisait perdre l'opportunité de mariages avantageux.

\section{SUMMARY}

The purpose of this work is to contribute to divulge the reasons of the conflict that implies the redemption, studying its effects through the analysis of the economic charges that the above mentioned tax, serfdom rights and other constraints supposed for the peasantry who was to pay them.

We talk about the origin of serfdom rights, about their establishment on the peasantry in the farms, about the impact of the "Sentencia de Guadalupe» -that does not only affect serves, but also other farmers- about legal casuistry, about who was to pay them, which was the amount and in what proportion it was payed. We also tackle the lack of effectiveness of the right of mishandle.

We can thus conclude that apart from the intestates and in some cases, few though, from the redemption, serfdom rights only overburdened the poorest farmers, because well-off farmers were only hindered in their possibilities of economic improvement by the obstacle that represented the prohibition to abandon the farm, which was an obstacle for the land market and which prevented profitable marriages. 